\title{
Antenatal screening for hepatitis B virus in HIV-infected and uninfected pregnant women in the Tshwane district of South Africa
}

\author{
Q Diale, ${ }^{1}$ MB ChB, FCOG; R Pattinson, ${ }^{1,2}$ MB ChB, FCOG, MD, FRCOG; R Chokoe, ${ }^{1}$ MB ChB, MMed (O\&G); \\ L Masenyetse, ${ }^{2}$ BSc Hons, MSc; S Mayaphi, ${ }^{3}$ MB ChB, FC Path (SA) Virol, MMed Path (Virol) \\ ${ }^{1}$ Maternal and Infant Health Care Strategies Unit, Department of Obstetrics and Gynaecology, School of Medicine, \\ Faculty of Health Sciences, University of Pretoria, South Africa \\ ${ }^{2}$ South African Medical Research Council, Gauteng, South Africa \\ ${ }^{3}$ Department of Medical Virology, School of Medicine, Faculty of Health Sciences, University of Pretoria, South Africa, and \\ National Health Laboratory Service - Tshwane Academic Division, Pretoria
}

Corresponding author: Q Diale (qdiale@hotmail.com)

Background. Despite enormous strides in preventing hepatitis B virus (HBV) infection, perinatal transmission still contributes significantly to HBV epidemiology worldwide; this could account for approximately $50 \%$ of chronically infected individuals.

Objective. To assess the need for HBV screening in antenatal clinics in the HIV/AIDS era.

Methods. This was a retrospective study conducted at the antenatal clinic of 1 Military Hospital, Tshwane, South Africa. Laboratory data for HBV, HIV and CD4 count were obtained and analysed for the period January 2008 - December 2013.

Results. A total of 2513 patients' results were retrieved and 2368 patients were enrolled as both their HBV and HIV serology results were available. The mean age of participants was 29 years (range 14 - 46). HIV prevalence in this study was $20.5 \%$ ( $95 \%$ confidence interval (CI) 0.189 - 0.222). The median CD4 count in HIV-infected patients was 522 cells/ $\mu \mathrm{L}$ (interquartile range 370 - 711). There was an overall HBV prevalence of $0.8 \%$ (95\% CI $0.005-0.011)$. The hepatitis B surface antigen (HBsAg) prevalence was significantly higher (2.1\%) among HIV co-infected compared with HIV-uninfected patients $(0.4 \%)(p=0.0001)$. Hepatitis e antigen (HBeAg) positivity was $30 \%$ in the HIV co-infected compared with $37.6 \%$ in the HIV-uninfected individuals $(p=0.7400)$.

Conclusion. This study showed a significantly higher HBV prevalence in HIV-infected compared with HIV-uninfected patients. The comparable HBeAg prevalence between the two groups indicates that both were at an increased risk of vertical transmission, therefore demonstrating a need for antenatal screening for HBV. Since antenatal screening is often not affordable in low-income countries, administration of $\mathrm{HBV}$ vaccine at birth is needed for prevention of vertical transmission.

S Afr Med J 2016;106(1):97-100. DOI:10.7196/SAMJ.2016.v106i1.9932

Hepatitis B virus (HBV) infection and its complications cause substantial medical and financial burdens to the healthcare system, and have become a major global public health concern. ${ }^{[1]}$ A global estimate is that 240 million individuals are chronically infected with $\mathrm{HBV}^{[2]}$ South Africa (SA) had an estimated $10 \%$ prevalence of $\mathrm{HBV}$ in the prevaccination era, with a significant reduction after the introduction of neonatal vaccination in 1995, as shown in recent studies. ${ }^{[3]}$ The prevalence of chronic carriage of HBV in SA blacks is estimated to be $5-16 \%$ in rural males, $8-9 \%$ in urban males, $4-12 \%$ in rural females and $2.7-4 \%$ in urban females. ${ }^{[4]}$

Despite enormous strides in preventing HBV infection, perinatal transmission continues to contribute significantly to HBV epidemiology worldwide and could account for approximately $50 \%$ of chronically infected individuals. ${ }^{[1]}$ The horizontal route of transmission has been reported to be the predominant mode of HBV transmission in $\mathrm{SA},{ }^{[4,5]}$ despite numerous African studies that have reported that perinatal vertical transmission occurs in $2-30 \%$ of infants born to HBV-infected mothers. ${ }^{[6-8]}$

In the absence of immunoprophylaxis, perinatal transmission occurs in $10-20 \%$ of women who are seropositive for hepatitis B surface antigen (HBsAg) but seronegative for hepatitis e antigen (HBeAg), and up to $90 \%$ of perinatal transmission occurs in women who are seropositive for both HBsAg and HBeAg. ${ }^{[9]} \mathrm{HBeAg}$ is a surrogate marker of high $\mathrm{HBV}$ viral load, as it is positive during the high replicative phase of $\mathrm{HBV}^{[9]}$ The risk of progression of acute to chronic $\mathrm{HBV}$ infection is inversely proportional to the age at which the infection was acquired. HBV infection is associated with a partial immune tolerance in infected infants and therefore results in a $95 \%$ chance of chronicity, compared with $30 \%$ in children aged $1-5$ years and $<5 \%$ in adults. ${ }^{[10]}$ Chronic hepatitis B sequelae include cirrhosis, hepatic carcinoma, glomerulonephritis and end-stage renal disease in children. ${ }^{[1]}$ Risk factors known to predispose to perinatal transmission include maternal $\mathrm{HBeAg}$ positivity, $\mathrm{HBsAg}$ titre, detectable HBV DNA, acute hepatitis B acquired in pregnancy, a history of threatened preterm labour and specific allelic mutations in maternal HBV ${ }^{[12]}$ The risk of vertical transmission is higher during the intrapartum period (at or near the time of birth) and is reported to result from exposure of the neonate to maternal blood and secretions during delivery. Intrauterine transmission of $\mathrm{HBV}$ is rare, accounting for $<5 \%$ of infants born to HbeAg- and HBsAg-positive mothers. It is understood to result from transplacental leakage of HBeAg-positive maternal blood during uterine contractions in pregnancy, and also from the disruption of placental membranes. ${ }^{[9,13]}$

Antenatal screening and administration of the birth-dose HBV vaccine and immunoglobulins are known to be $95 \%$ effective in reducing vertical transmission of $\mathrm{HBV}^{[11,14]}$ In SA, universal maternal antenatal screening is not practised in the public sector. The HBV immunisation schedule in SA introduced in 1995 initiates HBV vaccination at 6 weeks of age, with subsequent doses at 10 and 14 weeks. 
Sub-Saharan Africa is also highly endemic for HIV/AIDS, which shares a common route of transmission with HBV ${ }^{[15,16]}$ Local studies have shown a higher HBV prevalence in HIV co-infected individuals compared with their HIV-uninfected counterparts. ${ }^{[17,18]}$

\section{Objective}

To assess the need for HBV screening in antenatal clinics in the era of HIV/AIDS.

\section{Methods}

This was a retrospective study conducted at the antenatal clinic of 1 Military Hospital in Tshwane, which offered universal hepatitis $B$ antenatal screening and HIV testing to patients attending its antenatal clinic. During the study period (2008 - 2013), a total of 2513 patients' results were retrieved in the laboratory information system (LIS) for the antenatal clinic of 1 Military Hospital, Tshwane, SA. Of these patients, 2368 were enrolled in this study as they had both HIV and HBV results. Those who did not have both results were excluded (Fig. 1). Laboratory data for the period of January 2008 to December 2013 were retrieved from the LIS and results for $\mathrm{HBV}$ (HBsAg, HBeAg), HIV and CD4 count were collected and analysed. Axsym immunoassays (Abbott Diagnostics, Germany) were used for HBV and HIV serology, after which HIV confirmation was done on Vironostika HIV assay (bioMérieux, USA). Rapid HIV tests were also used for HIV diagnosis. Demographic data such as patient age were also retrieved. Ethical approval was received from the ethics committees of 1 Military Hospital and the University of Pretoria (6/2013).

\section{Data analysis}

Descriptive statistics consisting of summary statistics (i.e. mean, range) for numerical data and frequencies for categorical data were used. Comparison between the groups was done using a two-sample $t$-test for proportions. The software used was Stata 13

\begin{tabular}{|c|c|c|c|}
\hline $\begin{array}{l}\text { Age } \\
\text { (years) }\end{array}$ & $\begin{array}{l}\text { HBV- } \\
\text { positive }\end{array}$ & $\begin{array}{l}\text { HBV- } \\
\text { negative }\end{array}$ & Total \\
\hline$\leq 18$ & 0 & 27 & 27 \\
\hline $19-24$ & 3 & 558 & 561 \\
\hline $25-29$ & 3 & 690 & 693 \\
\hline $30-34$ & 7 & 592 & 599 \\
\hline$\geq 35$ & 5 & 483 & 488 \\
\hline Total & 18 & 2350 & 2368 \\
\hline
\end{tabular}

(StataCorp, USA). A $p$-value of $<0.05$ was considered statistically significant.

\section{Results}

The mean age of the participants was 29 years (range 14 - 46). Twenty-seven patients' results were in the under-18 years category, and none of them was HBsAg-positive (Table 1). HIV prevalence in the whole group was $20.5 \%$ ( $95 \%$ confidence interval (CI) $0.189-0.222$ ). The median CD4 count was 522 cells/ $\mu \mathrm{L}$ (interquartile range 370 $711)$ in the HIV-infected women. There was an overall HBV prevalence of $0.8 \%$ (95\% CI 0.005 - 0.011). The HBsAg prevalence

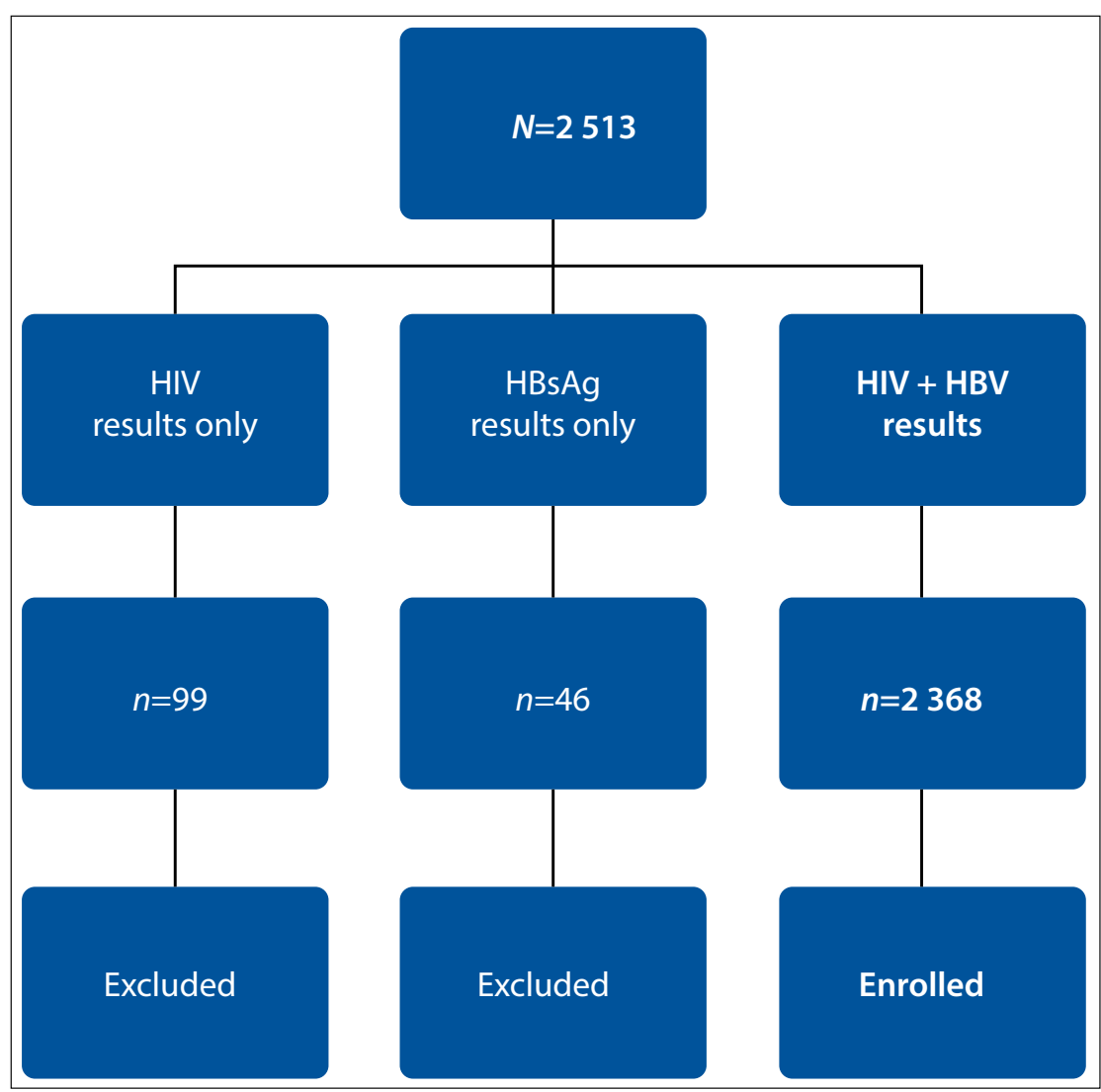

Fig. 1. Algorithm showing how patients were enrolled into this study. Only those who had both HIV and $H B V$ results were enrolled.

Table 2. HBsAg prevalence among HIV-infected v. HIV-uninfected patients

\begin{tabular}{llll}
\hline & $\begin{array}{l}\text { HIV-infected } \\
(N=\mathbf{4 8 6})\end{array}$ & $\begin{array}{l}\text { HIV-uninfected } \\
(N=1 \text { 882 })\end{array}$ & $\boldsymbol{p}$-value \\
\hline HbsAg-positive, $n(\%)$ & $10(2.1)$ & $8(0.4)$ & 0.0001 \\
$(95 \% \mathrm{CI})$ & $(0.008-0.034)$ & $(0.001-0.007)$ &
\end{tabular}

Table 3. HBeAg prevalence among HIV-infected v. HIV-uninfected patients

\begin{tabular}{|c|c|c|c|}
\hline & HIV-infected $(N=10)$ & HIV-uninfected $(N=8)$ & $p$-value \\
\hline $\begin{array}{l}\text { HBeAg-positive, } n(\%) \\
(95 \% \mathrm{CI})\end{array}$ & $\begin{array}{l}3(30.0) \\
(0.016-0.584)\end{array}$ & $\begin{array}{l}3(37.5) \\
(0.395-0.710)\end{array}$ & 0.7400 \\
\hline
\end{tabular}


positivity in the under-18 age group in this study (Table 1) is suggestive of HBV prevention from vaccination, as these patients probably received HBV vaccination (introduced in SA in 1995) in childhood. It was not surprising to see that HBV prevalence was fivefold higher in HIV-infected as opposed to HIV-uninfected pregnant women (Table 2). This finding has been reported in other SA studies. ${ }^{[17,18]} \mathrm{A}$ study in pregnant women in KwaZulu-Natal (KZN) revealed a 7.4\% HBV prevalence in HBV-HIV co-infected patients. ${ }^{[20]}$ A study conducted on pregnant women delivering in a rural hospital in Malawi in 1998 reported that $8 \%$ of pregnant women had HBVHIV co-infection. ${ }^{[21]}$ The low co-infection rate of $2.1 \%$ in this study could be due to higher CD4 counts (median 522 cells $/ \mu \mathrm{L}$ ) in this study group as opposed to the median of 328 in the KZN study and the fact that it was conducted in a low HBV prevalence area of SA (i.e. an urban setting in Gauteng Province). ${ }^{[17]}$

Currently in SA, pregnant women are not screened for HBV in the public sector. This places the neonates of $\mathrm{HBV}$-infected mothers at risk of acquiring $\mathrm{HBV}$ infection, as $\mathrm{HBV}$ vaccination is only started at 6 weeks of age. HIV-infected pregnant women are now treated for both HBV and HIV according to the new prevention of mother-to-child transmission (PMTCT) guidelines initiated in April 2013, which offer tenofovir, lamivudine (or amtricitabine) and efavirenz as the first line of treatment regardless of CD4 count. Tenofovir, amtricitabine and lamivudine have activity against HBV and HIV, thereby reducing the chances of vertical transmission of both viruses. ${ }^{[12,22]}$

Interestingly, the prevalence of $\mathrm{HBeAg}$ in this study was comparable in the HIV-infected (30.0\%) and uninfected (37.5\%) groups $(p=0.7400)$ (Table 3$)$. This finding indicates that without HBV treatment in pregnancy, or immunoprophylaxis to the exposed babies, both HIV-infected and HIV-uninfected mothers would be at the same risk of transmitting the virus to their neonates. However, HIV-infected mothers receive treatment for HBV during pregnancy, as highlighted above. It is therefore now the HIV-uninfected mothers who are at a much higher risk of transmitting HBV to their babies. Without antenatal screening, these HBV-exposed babies would not be identified for post-exposure prophylaxis with HBV vaccine and immunoglobulins.

Omitting the birth dose of HBV vaccine results in an increased risk of $\mathrm{HBV}$ transmission to the neonate if the mother is $\mathrm{HBsAg}$ positive. ${ }^{[23]}$ The HBV vaccine is $70-95 \%$ effective in preventing perinatal infection when administered alone within 24 hours of birth. HBV immunoglobulins provide passive immunisation to infants born to HBsAg-positive women. Administering the $\mathrm{HBV}$ vaccine in combination with one dose of hepatitis B immunoglobulin within 24 hours of birth provides 85 - 95\% efficacy in preventing perinatal HBV infection. ${ }^{[23,24]}$ One study showed that the risk of HBV infection for infants born to HBsAg-positive mothers increased significantly when the first dose of hepatitis B vaccine was received after 7 days (odds ratio 8.6) compared with those vaccinated on days $1-3$ after birth. ${ }^{[8]}$ The SA Expanded Programme on Immunisation (EPI) initiates HBV vaccination only at 6 weeks of life. Sub-Saharan African studies have shown a $10-20 \%$ breakthrough HBV infection rate in those who receive a 6 -week dose compared with the birth-dose vaccination. ${ }^{[3,8]}$

The practice of universal antenatal HBV screening ensures that all women with HBV infection receive optimal medical care through HBV treatment, regardless of their HIV status, and that their neonates receive the appropriate post-exposure prophylaxis. However, in developing countries, antenatal screening may be costly and not feasible. ${ }^{[25]}$ Some countries with an intermediate or low prevalence of chronic HBV infection or limited resources reduce costs by not screening pregnant women, but recommend starting
HBV vaccination from birth without HBV immunoglobulins. This strategy is cost-saving but is of moderate efficacy compared with the high efficacy and higher cost of maternal screening plus passive and active immunisation of neonates. ${ }^{[9]}$ A strategy of administering HBV vaccine at birth would be applicable in the SA setting, as there is no antenatal screening in the public sector.

A study published by Guidozzi et al. ${ }^{[26]}$ in 1993, which found a low $\mathrm{HBeAg}$ prevalence of $4.6 \%$ in $\mathrm{HBsAg}$-positive pregnant women, concluded that it would not be cost-effective to screen for HBV in pregnant urban SA women. However, this study may have underestimated the prevalence of $\mathrm{HBV}$ and $\mathrm{HBeAg}$ as it was conducted in predominantly white and urban-born black women, who are known to have low prevalence of HBV. The proportion of rural-born women, known to have a high prevalence of $\mathrm{HBV},{ }^{[4]}$ was estimated at $10 \%$ in Guidozzi et al's study.

Our study has shown a high HBeAg prevalence of $30.0 \%$ and $37.5 \%$ in HIV-uninfected and infected individuals, respectively. Although the study was conducted in an urban setting, we do not know the birth origins of the study participants owing to the retrospective nature of this study. However, Gauteng is known to attract people from rural areas of SA to seek job opportunities. The current National Health Laboratory Service price for HBsAg is ZAR161.10. Screening for HBsAg in our cohort would therefore have cost the government ZAR381 484.80 to identify $18 \mathrm{HBV}$-infected patients. This amount could be spent on getting more than 69000 doses of HBV vaccine, as the government used to buy the multidose HBV vaccine (with 10 doses) at ZAR54.93 (excluding tax) from the Biovac company before the introduction of hexavalent vaccine (containing $\mathrm{HBV}$ vaccine) at 6,10 and 14 weeks (personal communication, Biovac staff, sales department, 20 November 2015). We therefore agree with Guidozzi et al's conclusion that it would not be cost-effective to screen for HBV in pregnant urban SA women. The HBV vaccine birth dose without immunoglobulins has an efficacy of at least $70 \%$ in preventing HBV infection. ${ }^{[23,24]}$ Therefore, in the absence of HBV screening in the SA public sector, HBV vaccine alone given at birth as part of EPI would prevent at least $70 \%$ of infections in neonates.

Giving a birth dose of HBV vaccine to all neonates would serve as post-exposure prophylaxis to those exposed to HBV during pregnancy, while also fulfilling the role of pre-exposure prophylaxis for all neonates. Our data support the recommendation made by Spearman and Sonderup ${ }^{[27]}$ that SA should implement a four-dose HBV vaccination schedule with just the addition of the birth-dose vaccine within 24 hours of delivery. This schedule would be slightly more costly but easier to implement as it does not disrupt the current $\mathrm{HBV}$ vaccination schedule. ${ }^{[27]} \mathrm{A}$ three-dose $\mathrm{HBV}$ vaccination schedule has also been proven to be effective in other parts of the world. $^{[25]}$

\section{Study limitations}

The limitations of this study include a small sample size and the absence of HBV viral load. We were also not able to trace the records of babies born to HBsAg-positive mothers to determine whether they received post-exposure prophylaxis and their HBV status.

\section{Conclusion}

This study showed a significantly higher HBV prevalence in HIVinfected as opposed to HIV-uninfected women. The comparable $\mathrm{HBeAg}$ prevalence between the two groups indicates that both groups were at an increased risk of vertical transmission, therefore demonstrating a need for antenatal screening for HBV. Since antenatal HBV screening is often not affordable in low-income countries, there is a high demand for a birth dose of HBV vaccine for prevention 
of vertical transmission to the neonates. We therefore recommend that the SA National Department of Health review its current HBV vaccination schedule to include a birth dose of $\mathrm{HBV}$ vaccine to cater for neonates exposed to HBV during pregnancy, particularly those born to HIV-uninfected women and to HBV-HIV co-infected mothers who neither booked for antenatal care nor received PMTCT late in pregnancy.

\section{References}

1. Espoti SD, Shah D. Hepatitis B in pregnancy: Challenges and treatment. Gastroentrerol Clin North Am 2011;40(2):355-372. [http://dx.doi.org/10.1016/j.gtc.2011.03.005] 2. Ott JJ, Stevens GA, Groegerb J, Wiersma ST. Global epidemiology of hepatitis B virus infection: New
estimates of age-specific HBsAg seroprevalence and endemicity. Vaccine 2012;30(12):2212-2219. estimates of age-specific HBsAg seroprevalence
[http://dx.doi.org/10.1016/j.vaccine.2011.12.116]

3. Burnett RJ, Kramvis A, Dochez C, Meheus A. An update after 16 years of hepatitis B vaccination in South Africa. Vaccine 2012;30(Suppl 3):C45-C51. [http://dx.doi.org/10.1016/j.vaccine.2012.02.021]

4. Kew MC. Hepatitis B virus infection: The burden of disease in South Africa. S Afr J Epidemiol Infect 2008;23(1):4-8.

5. Robson SC, Kirsch RE. National strategy for viral hepatitis: Recommendations and guidelines for management in South Africa. S Afr Med J 1991;80(4):347-358.

6. Vardas E, Mathai M, Blaauw D, McAnerney J, Coppin A, Sim J. Preimmunization epidemiology of hepatitis B virus infection in South African children. J Med Virol 1999;58(2):111-115. [http://dx.doi. org/10.1002/(SICI)1096-9071(199906)58:2<111::AID-JMV2>3.0.CO;2-B]

7. Sangare L, Sombie R, Combassere AW, et al. Antenatal transmission of hepatitis B virus in an area of HIV moderate prevalence, Burkina Faso. Bull Soc Pathol Exot 2009;102(4):226-229.

8. Howell J, Lemoine M, Thursz M. Prevention of materno-foetal transmission of hepatitis B in subSaharan Africa: The evidence, current practice and future challenges. J Viral Hepat 2014;21(6):381396. [http://dx.doi.org/10.1111/jvh.12263]

9. Chang M-h. Hepatitis B virus infection. Semin Fetal Neonatal Med 2007;12(3):160-167. [http://dx.doi. Chang M-h. Hepatitis B virus in
org/10.1016/.siny.2007.01.013]

10. Ocama P, Opio CK, Lee WM. Hepatitis B virus infection: Current status. Am J Med 2005;1 18(12):1413. e15-1413.e22. [http://dx.doi.org/10.1016/j.amjmed.2005.06.021]

11. MacLean B, Hess R. Seroprevalance of hepatitis $B$ surface antigen among pregnant women attending the Hospital for Women and Children in Koutiala, Mali. S Afr Med J 2012;102(1):47-49.
12. Ho V, Ho W. Hepatitis B in pregnancy: Specific issues and considerations. J Antivir Antiretrovir 2012;4(1):3. [http://dx.doi.org/10.4172/jaa.1000046]

13. Jonas MM. Hepatitis B and pregnancy: An underestimated issue. Liver International 2009;29(suppl 1):133-139. [http://dx.doi.org/10.1111/j.1478-3231.2008.01933.x]

14. Shi Z, Li X, Ma L, Yang Y. Hepatitis B immunoglobulin injection pregnancy to interrupt hepatitis B virus mother-to-child transmission: A meta-analysis. Int J Infect Dis 2010;14(7):e622-e634. [http://
vis virus mother-to-child transmission: A meta-analysis. Int J Infect Dis 2010;14(7):e622-e634. [http:// dx.doi.org/10.1016/j.ijid.2009.09.008

15. World Health Organization. Hepatitis B. Fact sheet No. 204. July 2012. http://www.who.int/ mediacentre/factsheets/ss204/en/ (accessed 3 September 2014).

6. Thio C. Hepatitis B virus infection in HIV-infected persons. Curr Hepatol Rep 2004;3(1):91-97. [http:// dx.doi.org/10.1007/s1 1901-004-0015-8]

7. Mayaphi SH, Rossouw TM, Masemola DP, Olorunju SA, Mphahlele MJ, Martin DJ. HBV/HIV coinfection: The dynamics of HBV in South African patients with AIDS. S Afr Med J 2012;102(3):157-162

18. Andersson MI, Maponga TG, Ijaz S, Theron G, Preiser W, Tedder RS. High HBV viral loads in HIVinfected pregnant women at a tertiary hospital. J Acquir Immune Defic Syndr 2012;60(1):4. [http:// dx.doi.org/10.1097/QAI.0b013e31825aeee7]

19. National Department of Health, South Africa. The 2012 National Antenatal Sentinel HIV \& Herpes Simplex Type-2 Prevalence Survey. Pretoria: NDoH. www.doh.gov.za (accessed 16 September 2014).

20. Thumbiran NV, Moodley D, Parboosing R, Moodley P. Hepatitis B and HIV co-infection in pregnant Thumbiran NV, Moodley D, Parboosing R, Moodley P. Hepatitis B and HIV co-infection in pregnant
women: Indication for routine antenatal hepatitis B virus screening in a high HIV prevalence setting. women: Indication for routine antenatal hepatitis B virus screening in a

21. Ahmed SD, Cuevas LE, Brabin BJ, et al. Seroprevalence of hepatitis B and C and HIV in Malawian pregnant women. J Infect 1998;37(3):248-251. [http://dx.doi.org/10.1016/S0163-4453(98)91983-1]

22. Chen $\mathrm{HL}$, Lee $\mathrm{CN}$, Chang $\mathrm{CH}$, et al. Efficacy of maternal tenofovir disoproxil fumarate in interruptin mother-to-infant transmission of hepatitis B virus. Hepatology 2015;62(2):375-386. [http://dx.doi. org/10.1002/hep.27837]

23. World Health Organization. Hepatitis B vaccines. Wkly Epidemiol Rec 2009;40(84):405-420. http:// www.who.int/wer/2009/wer8440.pdf (accessed 13 April 2015).

24. Centers for Disease Control and Prevention. Hepatitis B. http://www.cdc.gov/vaccines/pubs/ pinkbook/hepb.html (accessed 28 March 2015).

25. Van Herck K, van Damme P. Benefits of early hepatitis B immunization programs for newborns and infants. Pediatr Infect Dis J 2008;27(10):861-869. [http://dx.doi.org/10.1097/INF.0b013e318173966f] 26. Guidozzi F, Schoub BD, Johnson S, Song E. Should pregnant urban South African women be screened for hepatitis B? S Afr Med J 1993;83(2):103-105.

27. Spearman CWN, Sonderup MW. Preventing hepatitis B and hepatocellular carcinoma in South Spearman CWN, Sonderup MW. Preventing hepatitis B and hepatocellular carcinoma in South
Africa: The case for a birth-dose vaccine. S Afr Med J 2014;104(9):610-612. [http://dx.doi.org/10.7196/ SAMJ.8607]

Accepted 21 September 2015. 